\title{
RURALIDADE: DEFINIÇÕES E TIPOLOGIAS*
}

\author{
Francisco José Lopes de Sousa Diniz**
}

\section{INTRODUÇÃO}

O termo rural tem significados diferentes para diferentes pessoas. Desde uma paisagem bucólica até zonas remotas, atrasadas e com tradições ancestrais, passando por lugares onde se produzem alimentos e matérias-primas para o sector secundário, tudo cabe na definição do termo rural. A confusão fica a dever-se a algumas das características que, tradicionalmente, definem o mundo rural, tais como: actividade agrícola dos seus habitantes, forte dependência dos recursos naturais e extracção de matérias-primas, características que não esgotam as especificidades do mundo rural.

O número de habitantes que se dedicam a tempo inteiro à agricultura é, em muitas zonas rurais, tão pequeno que o estatuto rural tem pouco a ver com as explorações agrícolas. As indústrias extractivas têm vindo a conhecer uma redução do seu contributo para o valor final da produção, encontrando-se numa fase de recessão e de perda de postos de trabalho, na tentativa de se tornarem competitivas pela via da mecanização. Por outro lado, há novas características que ajudam a definir o mundo rural tornando-se essenciais na atribuição do que se denomina por ruralidade.

A relação económica entre espaço e distância constitui o cerne da questão da ruralidade para Castle (1991). A OCDE (1992) refere que as definições territoriais de ruralidade esquecem a importante dimensão socioeconómica e a diversidade de qualquer território classificado como rural.

A abertura do sistema socioeconómico esbateu ou fez, mesmo, desaparecer as antigas fronteiras espaciais que definiam um território como rural, tornando a abordagem espacial do mundo rural num conceito ultrapassado. $\mathrm{O}$ desenvolvi-

** Departamento de Economia e Sociologia/Universidade de Trás-os-Montes e Alto Douro. 
mento espectacular dos meios de comunicação e de transporte também se faz sentir no meio rural. O novo conceito de mundo rural não se baseia mais numa óptica espacial, mas sim numa série de redes que permanentemente recolocam o status de ruralidade pelas relações que se estabelecem entre as populações rurais com as da sua zona, região, país ou mesmo, de uma forma mais abrangente, com o resto do mundo.

Um outro aspecto que ajuda a definir o mundo rural consiste na qualidade inferior do seu nível de vida em relação aos centros urbanos. A utilização duma dicotomia tal como centro urbano/periferia rural logo coloca uma outra, a da superioridade/inferioridade. A inferior qualidade de vida (expressa em termos dos indicadores convencionais) que caracteriza o meio rural refere-se aos serviços sanitários, educativos, prestações sociais, oportunidades económicas, parque habitacional e infra-estruturas físicas.

Por fim, o mundo rural pode, ainda, ser melhor definido através das unidades socioeconómicas e de valores. Esta concepção também tem vindo a perder adeptos à medida que os agentes externos vão ganhando força e alargando a sua influência ao modo de vida das comunidades rurais.

Apesar da dificuldade de conceptualização do termo rural, pode dizer-se que, na essência, há três definições que entre si apresentam fortes inter-relações:

- definição sociocultural que pressupõe que o comportamento e as atitudes diferem entre os habitantes de zonas de baixa densidade populacional (rurais) e as de forte densidade (urbanas), associando-se aos rurais valores tradicionais. Esta visão tem uma importante vertente antropológica;

- definição ocupacional baseada na predominância de actividades económicas ligadas ao sector primário (agricultura, silvicultura, caça, pesca e indústrias extractivas). Esta distinção ocupacional deixou de ser determinante face à crescente integração dos agricultores nos mercados de trabalho não agrários. A pluriactividade é, hoje em dia, um elemento a ter presente no meio rural, de tal forma que a diferenciação ocupacional entre os rurais e os urbanos pode ser enganosa;

- definição ecológica que considera o rural como zonas de pequenos aglomerados com grandes espaços de paisagem aberta entre eles. Esta concepção implica uma definição de paisagem aberta e de grandes espaços.

Porém, para instituições como a UE e a OCDE, o mundo rural constitui um conjunto de regiões ou zonas com actividades diversas (agricultura, artesanato, pequena e média indústria, comércio e serviços, entre outras), assente tanto em pequenos aglomerados, aldeias e pequenas cidades, como em espaços naturais e áreas cultivadas. Com base neste conceito, o mundo rural representa cerca de 
$80 \%$ do território comunitário e nele habitam e/ou desenvolvem a sua actividade mais de $50 \%$ da população total da UE.

\section{MUTAÇÕES NOS MODELOS E NO ESPAÇO RURAL}

As mutações porque tem passado o espaço rural e as suas estruturas económicas e sociais tornam pertinente a análise do conteúdo conceptual do termo rural. Por um lado, reforça-se a relação com a natureza, como mero fornecedor de recursos naturais que faz das questões ambientais e da revalorização da paisagem o núcleo do pensamento das diferenciações espaciais; por outro, esbate-se a relação com a paisagem e a actividade agrícola, ao mesmo tempo que cresce o emprego nos sectores secundário e terciário, que confirma a vocação residencial do espaço.

Há um apego a análises dinâmicas do espaço que se traduz na eliminação da distinção rural/urbano em benefício da noção de local (em vez de rural). Definir as consequências destes movimentos contraditórios com vista a identificar novas divisões do espaço rural, ou seja, novas categorias espaciais, é o que, a partir de agora, se tentará explicar, integrando questões relacionadas com a dimensão ambiental.

A evolução da ruralidade será discutida tendo em atenção a sua relação, quer com a evolução socioeconómica geral, quer com o fenómeno urbano. Esta forma de abordagem proporciona sistemas explicativos, formas conceptuais e teóricas do termo rural e da sua evolução.

Para tornar mais clara a exposição, a noção de rural aparecerá indissolúvel da de urbano. Analisar-se-ão o grau de especificidade ou autonomia do termo rural em relação ao urbano e o tipo de interacção (dependência, contradição, absorção) que os une, particularmente no pós-guerra.

\subsection{Década de 50}

$\mathrm{Na}$ década de 50, contradição, senão o antagonismo, entre o urbano e o rural são palavras-chave na conceptualização clássica do termo rural. Ao campo alia-se a ideia de meio natural não restrito à natureza de per si, mas alargada à natureza cultivada/agricultada e produtora de matérias-primas. O campo define-se pela actividade agrícola e pelos camponeses, cuja função primeira é a de valorizar os recursos naturais de que são proprietários. Este conceito opõe-se ao urbano pela simples razão de que a cidade é um meio tecnológico que escapa completamente à natureza. A sua especificidade é outorgada pela existência de actividades industriais e de serviços sendo, por isso, um meio de acumulação dos factores trabalho e capital. $\mathrm{O}$ urbano/citadino, em termos sociais, aparece dividido entre a burguesia e a classe operária (Friedman, 1953). 
Se a oposição destas definições põe em destaque o seu carácter distinto e dicotómico, a contradição é mais evidente quando se analisa o tipo de relação existente entre as duas categorias. $\mathrm{O}$ meio rural fornece as cidades tanto de matéria-prima para a indústria e alimentos para as populações urbanas como de mão-de-obra, criando com a cidade uma relação em que a extracção, por parte desta, dos recursos naturais e humanos se faz em seu benefício. O êxodo rural é o processo espacial dominante neste modelo.

A especificidade da noção de ruralidade não põe de lado a diversidade, logicamente ligada às diferenças, quer do meio natural, quer da organização social da produção agrícola (sistema agrário). Nesta década, o êxodo rural era tido como algo de bom e natural para a normal evolução do processo de desenvolvimento sendo, inclusivamente, alimentado para além da população agrícola dos meios rurais por comerciantes e artesãos rurais. Tal contribuiu, ainda mais, para uma agricolização do meio rural.

Outros autores foram influenciados pela análise dicotómica das relações campo/cidade. Tönnies (1963) opõe radicalmente Gemeinschaft a Gesellschaft. Estes dois conceitos socioantropológicos, referentes à comunidade e à associação, cristalizam o contraste existente entro o campo e a cidade. A Gemeinschaft é a comunidade caracterizada pelo conhecimento mútuo, a imobilidade social e física e a homogeneidade cultural; enquanto que a Gesellschaft é uma associação caracterizada por relações contratuais impessoais e por um nível elevado de mobilidade social e espacial. Keyser (1962) põe em evidência o crescimento urbano como uma forma de exploração do mundo rural. Mendras (1959), ao referir as relações entre o campo e cidade, cria uma situação de compromisso ao afirmar:

Citadinos e rurais formam em certos aspectos uma sociedade única: eles participam na mesma civilização... No entanto, não existe uma solução de continuidade entre a metrópole, a grande cidade, a pequena cidade, a vila e a aldeia mas será abusivo criar um fosso entre os dois extremos. Todas as estatísticas revelam diferenças na intensidade e não contrastes.

\subsection{Década de 60}

A década de 60 caracterizou-se pelo milagre económico do crescimento que conheceu um ritmo significativo. Mathieu (1974) refere a urbanização do campo, enunciando um modelo que, antes de mais, põe fim à relação enunciada no anterior modelo, rejeitando a distinção entre rural e urbano tanto na vertente espacial como na social. A urbanização era considerada como um movimento irreversível, uma tendência tão forte que se transformava em lei do desenvolvimento espacial, nada mais restando do que assistir ao fim do mundo rural e ao estabelecimento de um espaço contínuo urbano/rural. A noção de rural desaparece conjuntamente com a ideia de espaço natural. A absorção cultural do meio rural, dos campesinos ou dos rurais faz-se por um processo de assimilação e integração da cultura urbana. 
O êxodo rural é reconhecido mas justificado pela modernização homogénea do espaço como um todo. A distinção entre a cidade e o campo faz-se com base nas diferenças entre as condições de vida, as estruturas sociais e o grau de pressão do modo de vida urbano. O processo de difusão do modo de vida urbano faz com que se atenue a clivagem entre os modos de vida rural e urbano. Rambaud (1969) afirma:

Apelidar-se-á urbanização não apenas a influência que a cidade exerce sobre o campo, nem o crescimento da população das cidades pela vinda dos rurais, mas a invenção de um modo de vida em via de se tornar universal e realizar a unidade do Homem social.

Assiste-se, nesta altura, a uma diversificação das actividades produtivas rurais que deixam de ser exclusivamente agrícolas. Inicia-se um processo de industrialização do meio rural e de uma terciarização da economia rural, por via da actividade turística.

\subsection{Década de 70}

$\mathrm{Na}$ década de 70, com o surgir de actividades não-agrícolas do espaço rural, assiste-se a um reverso ideológico em relação à década precedente. As noções de campo e campesinato começam a ser valorizadas pela corrente neo-ruralista (Léger-Hervieu 1979). O espaço rural não se identifica com actividades exclusivamente agrícolas mas é, igualmente, dotado de características que o diferenciam do urbano (por exemplo, densidade demográfica, quota do trabalho assalariado, preponderância das pequenas e médias empresas, paisagem com usos múltiplos agrícolas e habitat natural). Há como que um regresso à abordagem dicotómica, um retorno à natureza e ao espaço rural harmonioso e rico em recursos naturais. O espaço rural aparece como uma resposta à concentração urbana e a sua análise faz-se pela observação das transformações económicas e sociais em consequência da diversificação das actividades.

\subsection{Década de 80}

A década de 80 é marcada pela tensão existente entre duas tendências: uma faz desaparecer ou atenua as diferenças entre o rural e o urbano, banalisando a especificidade do espaço rural em benefício de um conceito ubiquista de local (Mathieu, 1985); e outra, pelo contrário, reforça a distinção entre rural e urbano, reintroduzindo a noção de natureza pela via dos problemas ambientais. A crise do modelo de desenvolvimento (crise do fordismo e das relações internacionais) que se instalou neste decénio reforçou a concepção do espaço rural de forma antagónica, ignorando os que não podem ser entendidos como pólos e os que não são competitivos. São os tempos do liberalismo produtivista. Os grandes temas são o desenvolvimento local, os recursos locais e o desenvolvimento endógeno e autocentrado. A interdisciplinaridade é uma palavra-chave que faz a ponte entre o 
desenvolvimento local/rural e o ambiente. Uma nova definição da especificidade do espaço rural é caracterizada por certas fragilidades naturais em relação ao espaço urbano, sem que necessariamente tenham que ser do tipo contraditório ou de dependência.

Quadro n.* 1

EVOLUÇÃO DO CONCEITO DE RURALIDADE DE 1950/1980

\begin{tabular}{|c|c|c|c|}
\hline Períodos & Definição de rural & Rural/urbano & Tipologias \\
\hline Década de 50 & $\begin{array}{l}\text { - Meio natural } \\
\text { - Meio agrícola } \\
\text { - Agricultura } \\
\text { - Exxodo rural } \\
\text { - Agricolarização }\end{array}$ & $\begin{array}{l}\text { Cidade versus campo } \\
\text { Contradições }\end{array}$ & $\begin{array}{l}\text { Tipos de agricultura } \\
\text { Tipos de paisagens }\end{array}$ \\
\hline Década de 60 & $\begin{array}{l}\text { - Rural = população agrícola } \\
\text { - Fim da noção de natureza } \\
\text { - Crescimento da população } \\
\text { não agrícola }\end{array}$ & $\begin{array}{l}\text { - Urbanização do campo } \\
\text { - Absorção/integração } \\
\text { - Rural = urbano } \\
\text { - Transformações do } \\
\text { espaço rural } \\
\text { - Diferenciação }\end{array}$ & $\begin{array}{l}\text { Tipos de espaços rurais } \\
\text { com base na função } \\
\text { e na integração urbana }\end{array}$ \\
\hline Década de 70 & $\begin{array}{l}\text { - Campo reinventado } \\
\text { - Neo-naturalismo } \\
\text { - Espaço livre para o citadino } \\
\text { - Continuidade da tendência } \\
\text { anterior } \\
\text { - Abrandamento do } \\
\text { êxodo rural } \\
\text { - Crise de emprego }\end{array}$ & $\begin{array}{l}\text { - Rural \# urbano } \\
\text { - Ambiente } \\
\text { - Crise urbana } \\
\text { - Contradição } \\
\text { - Anexação } \\
\text { - Concorrência } \\
\text { - Cobiça }\end{array}$ & $\begin{array}{l}\text { Multiplicidade de } \\
\text { tipologias (teorização) }\end{array}$ \\
\hline Década de 80 & $\begin{array}{l}\text { - Local/rural } \\
\text { - Ambiente } \\
\text { - Industrialização rural } \\
\text { - Inversão da tendência } \\
\text { do êxodo rural }\end{array}$ & $\begin{array}{l}\text { - Rural = local } \neq \text { urbano } \\
\text { - Urbano } \\
\text { - Regresso à especificidade } \\
\text { do termo rural } \\
\text { - Interacção }\end{array}$ & $\begin{array}{l}\text { - Multicritério } \\
\text { - Fragilidade } \\
\text { - Consideração de } \\
\text { critérios sociais }\end{array}$ \\
\hline
\end{tabular}

Fonte: Adapado de Mathieu, N., "La notion de rural et les rapports ville-campagne em France: Des années cinquante aux années quatre-vingts", Économie rurale, $\mathbf{n} .^{\circ} 197,1990$.

A definição de áreas rurais e urbanas tem animado um aceso e controverso debate nos meios académicos ao longo de vários anos. A teorização, por exemplo, das relações entre o rural e o urbano, segundo Cloke et al (1980), tem vindo a ser 
observada na forma de um modelo cíclico, o qual não conduz, necessariamente, a uma representação acurada das mutações nos modelos que, ao longo do tempo, têm vindo a ocorrer nessas mesmas relações (ver fig. n. ${ }^{\circ} 1$ ).

\section{Figura n. 1 \\ MODELO CÍCLICO DAS RELAÇÕES ENTRE O RURAL E O URBANO}

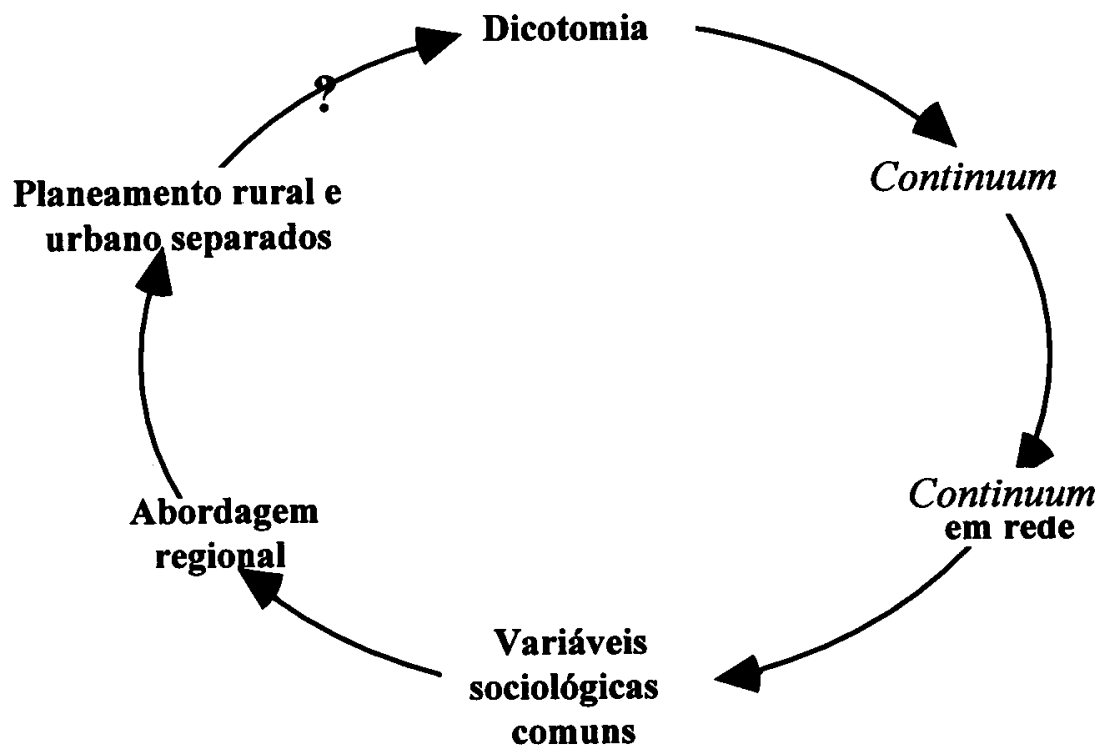

Fonte: Cloke et al (1980).

O gráfico descreve a oscilação na conceptualização das relações entre o rural e o urbano, analisando as duas formas de continuum entre dois pólos, de acordo com as ideias expressas por Bailey (1985). No entanto, será de realçar que, ao fechar-se, o ciclo poderia cair num separatismo entre o planeamento rural e urbano. Esta tendência veicula a ideia de que a gestão dos problemas das regiões rurais requer uma atenção individualizada.

Este modelo sumário traz à cena duas atitudes básicas na definição de ruralidade. Uma delas assenta na ideia que não existe uma forma não ambígua de definir áreas rurais (Moseley et al, 1977) e, por isso, um debate prolongado sobre as várias definições revelar-se-á estéril. A outra, personificada por Show (1979), refere que a distorção entre áreas rurais e urbanas encontra as suas raízes no foro psicológico, na maioria das tentativas de subdividir uma região. 
Phillips et al (1984) apontam quatro razões para a manutenção de áreas rurais como unidades individualizadas de investigação: (1) a necessidade da existência de estudos rurais para contrabalançar os que se fazem sobre os meios urbanos; (2) o requisito pragmático de categorias analiticamente convenientes do rural e do urbano; (3) a necessidade de expor muitos dos mitos românticos rurais que têm sido alimentados por ciências sociais historicamente anti-urbanas; (4) a crença que as regiões rurais têm características próprias que as distinguem das urbanas.

\section{AS RELAÇÕES ENTRE O RURAL E O URBANO NA CONCEPÇÃO DE TIPOLOGIAS DO MUNDO RURAL}

Para uma melhor compreensão das diferentes tipologias concebidas para o mundo rural e as implicações no desenvolvimento rural, seria importante tecer algumas considerações acerca dos desequilíbrios que, na Europa dos quinze, tenderiam a agravar-se nos últimos decénios. A não ser que as políticas regionais se submetam a interesses de âmbito regional ou, na impossibilidade de ocorrência deste facto, as regiões sejam compensadas pelas perdas a que ficam sujeitas ao integrar-se no todo da União Europeia, os desequilíbrios agravar-se-ão.

De uma forma resumida, os fundamentos teóricos da política regional podem ser identificados por uma abordagem neo-clássica, keynesiana e do crescimento endógeno. Trata-se, num e noutro caso, de abordagens redistributivas.

As duas primeiras abordagens assentam na mobilidade de factores e foram desenvolvidas nos anos 50 e 60 . Na teoria neo-clássica há a destacar a política de infra-estruturas e a política dos incentivos ao investimento (capital), que se enquadram, tanto no modelo da economia do bem-estar e na análise custos-benefícios, como no modelo de crescimento neo-clássico. As restrições administrativas aos incentivos ao investimento, a localização de investimentos empresariais públicos, os acordos de planeamento com grandes empresas privadas, as transferências públicas e o crescimento do emprego no sector público são os instrumentos em que assenta a abordagem keynesiana, quer pelo modelo do desenvolvimento acumulado, quer pelo modelo das exportações, ou mesmo o dos pólos de crescimento.

O não funcionamento, na prática, da difusão do desenvolvimento baseado no modelo keynesiano conduziu a uma abordagem do crescimento endógeno na década de 70, tendo como base o custo de produção e discutindo temas centrados:

- na descentralização administrativa;

- na autonomia regional;

- no planeamento da cooperação entre o sector público e o privado;

- no delineamento de políticas a nível regional e sub-regional;

- nos incentivos à reestruturação industrial; 
- nos incentivos fiscais à criação de emprego;

- no estudo do desemprego;

- e nas políticas de criação de emprego e de pequenas empresas.

Os vários modelos apresentados diziam respeito ao desenvolvimento autónomo em termos da divisão funcional e intra-regional, quer do trabalho quer das compensações, e da capacidade do sistema empresarial local.

$\mathrm{O}$ crescimento endógeno nos anos $\mathbf{8 0}$ evoluiu no sentido de uma abordagem em que o binómio inovação-difusão passa a ser a palavra-chave. Os diferentes modelos (incubação, ciclo produtivo, localização de serviços, contra-urbanização, absorção cultural) preocuparam-se com os seguintes aspectos:

- serviço de apoio empresarial de investigação e de desenvolvimento (I/D);

- incentivos ao desenvolvimento das exportações;

- formação profissional e de gestão;

- mobilidade sectorial do factor trabalho;

- políticas ambientais;

- infra-estruturas tecnológicas;

- políticas de sistemas metropolitanos;

- capital especulativo;

- e recursos endógenos locais e regionais.

Face a este enquadramento da evolução dos fundamentos teóricos da política regional, nomeadamente, por um lado, as abordagens keynesianas e, por outro, do crescimento endógeno, que - como já se disse - não são mais do que abordagens redistributivas, a consideração do desenvolvimento regional na Europa pode ser ainda vista segundo um outro prisma que se designará por abordagem de compensação.

Numa abordagem redistributiva, o objectivo da política regional, tal como o da política social, consiste na obtenção de uma distribuição mais equitativa do rendimento e do bem-estar nas diferentes regiões. No entanto, enquanto as políticas sociais se dirigem para grupos ou indivíduos de uma população desfavorecida, a política regional pretende beneficiar a totalidade da população de regiões desfavorecidas, que detêm um nível de vida muito abaixo da média nacional ou mesmo supra-nacional. Para além disso, as políticas sociais visam a distribuição de serviços públicos, as transferências de rendimentos no seio da população, constituindo o principal objectivo das políticas regionais a re-afectação da produção para redistribuir oportunidades de emprego entre as diferentes regiões.

Nesta abordagem, uma vez que o nível e taxa de crescimento do rendimento nacional é, duma maneira geral, considerado como um dado exógeno, o único objectivo centra-se à volta da tarefa de mudar a forma como o rendimento se dis- 
tribui, privilegiando as regiões menos prósperas. O problema torna-se mais complexo quando, do lado da oferta, o nível do rendimento agregado se encontra ligado à localização e concentração da produção. Do lado da procura, a política regional implica, normalmente, um aumento da despesa pública, o que pode colidir com o objectivo nacional de diminuição do deficit público, de uma diminuição da taxa de inflação ou mesmo de um desagravamento do deficit da balança de pagamentos. Há um conflito entre a equidade distributiva e a eficiência pretendida ao nível dos agregados macro-económicos.

Numa abordagem da política regional pela via do crescimento endógeno, os seus objectivos são:

- o pleno emprego dos recursos locais e o aumento da sua produtividade; a retenção do valor acrescentado no local;

- a preservação e a valorização dos valores da cultura e dos costumes locais. Os recursos locais vão desde:

- a força de trabalho;

- o know-how local;

- à especialização sectorial local;

- à estrutura social local;

- ao ambiente local e urbano, entre outros.

A política regional consistirá na relação da mais eficiente afectação destes recursos a diferentes sectores produtivos e na promoção do progresso tecnológico, aumentando a competitividade da produção regional. $O$ que está em causa não são certos indicadores do nível de vida, mas sim o desequilíbrio no uso dos recursos locais nas várias regiões. Nesta linha de pensamento, as diferenças regionais, na taxa de desemprego e na produtividade dos recursos locais, podem ser explicadas através da inflexibilidade dos preços que não deixam funcionar o mercado e da imobilidade inter-regional de recursos, traduzida na ineficiência e na perda de potencialidades locais de desenvolvimento.

A eficácia de uma política regional depende mais da capacidade para maximizar a produção local, pelo aumento do emprego e da produtividade, do que do nivelamento das disparidades de níveis de vida. Enquanto que a abordagem redistributiva assenta num procedimento top-down (de cima para baixo), para o cálculo do produto bruto a custo regional de factores, o crescimento-endógeno implica uma postura bottom-up (de baixo para cima), na análise do produto nacional visto como uma soma de produtos regionais. Esta última abordagem tem por base um fundamento económico mais rigoroso, associando-se mais às características de uma unidade económica. Ao aderir a um qualquer tipo de união, quer económica quer política, todos os países e regiões vêem a sua autonomia, em termos de política económica, transferida para instituições supra- 
nacionais. Este facto será de algum modo compensado pelo apoio que estas instituições supranacionais possam vir a dar a regiões ou países menos desenvolvidos.

A abordagem por via da compensação, ao contrário da redistributiva, parte do pressuposto que a política regional das instituições Europeias pode mobilizar recursos que compensem, de algum modo, os custos de oportunidade oriundos da entrada para uma união económica e política. Por outras palavras, países, regiões ou localidades devem ser compensados através de medidas específicas para obviar ao acréscimo de custos que as novas políticas definidas pela adesão a essa união lhes tenham, eventualmente, causado ou possam vir a causar.

Esta compensação torna-se, assim, difícil de realizar e o principal problema está na forma de se desembaraçar dos efeitos de medidas avulsas e simultâneas da política económica e separá-los de outros choques económicos exógenos. Enquanto que na redistribuição os recursos a afectar a políticas regionais podem ser decididos pelas disparidades verificadas no nível de vida, na compensação outras variáveis entram no processo de decisão, ficando elas mesmo sujeitas a diferentes hipóteses de intervenção.

Se tivermos em mente o facto que os desequilíbrios verificados no seio da União Europeia se fazem sentir, em primeiro lugar, nos diferentes estados de desenvolvimento dos vários países que a integram e, em segundo lugar ao nível interno de cada um deles, constatamos que esses desequilíbrios assentam na dicotomia do desenvolvimento urbano crescente e no desacelerar do desenvolvimento rural.

De acordo com uma publicação do World Bank (1991), a percentagem de população rural em 1989 variava entre os $3 \%$ da Bélgica e os 67\% de Portugal, tendo somente em linha de conta os 15 países membros da União Europeia (ver Quadro n. ${ }^{\circ}$ 2). 
Quadro n. ${ }^{\circ} 2$

EVOLUÇÃO DA POPULAÇÃO RURAL NA UNIÃO EUROPEIA

\begin{tabular}{|c|c|c|c|c|c|c|c|c|c|}
\hline & \multicolumn{3}{|c|}{ Populaçăo (em milhöes) } & \multicolumn{3}{|c|}{$\begin{array}{c}\text { Pop. Rural } \\
\text { (\% da pop. total) }\end{array}$} & \multicolumn{3}{|c|}{$\begin{array}{l}\text { Pop. Act. Agric. } \\
(\%)\end{array}$} \\
\hline & 70 & 80 & 89 & 70 & 80 & 89 & 70 & 80 & 89 \\
\hline Áustria & 7,426 & 7,554 & 7,598 & 48 & 45 & 43 & 15 & 9 & 7 \\
\hline Bélgica & 9,638 & 9,847 & 9,886 & 6 & 5 & 3 & 5 & 3 & 3 \\
\hline Dinamarca & 4,929 & 4,780 & 4,974 & 20 & 16 & 14 & 17 & 7 & 5 \\
\hline Espanha & 33,779 & 37,386 & 39,161 & 34 & 27 & 22 & 26 & 17 & 10 \\
\hline Finlândia & 4,606 & 4,780 & 4,974 & 50 & 40 & 40 & 20 & 12 & 9 \\
\hline França & 50,772 & 53,880 & 56,119 & 29 & 27 & 26 & 14 & 9 & 6 \\
\hline Grécia & 8,793 & 9,643 & 10,039 & 48 & 42 & 38 & 42 & 31 & 22 \\
\hline Irlanda & 2950 & 3,401 & 3,537 & 48 & 45 & 41 & 26 & 19 & 14 \\
\hline Itálilia & 58,822 & 56,434 & 57,537 & 36 & 34 & 32 & 19 & 2 & 8 \\
\hline Luxemburgo & 0,340 & 0,365 & 0,379 & 32 & 22 & 16 & 8 & 5 & 3 \\
\hline Páses-Baixos & 13,039 & 14,150 & 14,828 & 14 & 12 & 12 & 7 & 6 & 4 \\
\hline Portugal & 9,044 & 9,766 & 10,333 & 74 & 71 & 67 & 32 & 26 & 12 \\
\hline Reino Unido & 55,632 & 56,330 & 57,270 & 12 & 9 & 8 & 3 & 3 & 2 \\
\hline RFA & 60,651 & 61,566 & 61,337 & 19 & 16 & 14 & 7 & 6 & 4 \\
\hline Suécia & 8,043 & 8,310 & 8,485 & 19 & 17 & 16 & 8 & 6 & 3 \\
\hline Total & 323,464 & 338,535 & 346,615 & 27 & 24 & 22 & 16 & 11 & 7 \\
\hline
\end{tabular}

Fonte: World Bank (1991).

Do quadro acima consta também a evolução da população activa na agricultura. Será de realçar a circunstância de que a população agrícola tem vindo a diminuir, representando o seu peso em relação à população activa total, em 1992, menos de metade do que em 1970. Desta situação pode concluir-se que a população rural cada vez tem a ver menos com a agricultura, o que se traduz, segundo alguns autores, no fenómeno da urbanização do mundo rural.

Como mais adiante se analisará, o conceito de ruralidade é muito mais complexo do que a dicotomia rural/urbano explicita, uma vez que não se esgota pela observação de índices meramente quantitativos.

De acordo com a mesma publicação, no quadro n. 3 apresentam-se algumas definições nacionais utilizadas para classificar um aglomerado populacional como rural. Por exemplo, esta classificação, elaborada com base num só critério 
- dimensão da população -, encerra dentro de si própria a sua grande limitação. A simplicidade do critério não significa que haja uniformidade quanto à dimensão da população, que vai desde os $\mathbf{2 0 0}$ habitantes em todos os países nórdicos até aos 10000 habitantes no caso de Portugal (Diniz: 1995).

\section{Quadro n.. 3 \\ ALGUNS EXEMPLOS DE CRITÉRIOS NACIONAIS PARA CLASSIFICAR ZONAS RURAIS}

\begin{tabular}{|c|c|}
\hline Áustria: & Aglomerados populacionais com menos de 1000 habitantes, excluindo certas áreas (excepto complexos turísticos) \\
\hline Dinamarca: & Comunidades (Gemeinden) de menos de 5000 habitantes \\
\hline Escócia: & Aglomerações com menos de 1000 habitantes \\
\hline Espanha: & Municípios com menos de 2000 habitantes \\
\hline França: & $\begin{array}{l}\text { Comunidades que englobam una aglomeração de menos de } 2000 \text { habitantes que vivem em casas contínuas ou afasta } \\
\text { das em não menos de } 200 \mathrm{~m} \text { entre elas }\end{array}$ \\
\hline Grécia: & População de municípios com menos de 2000 habitantes \\
\hline Luxemburgo: & Aglomerados populacionais com menos de 2000 habitantes \\
\hline Países-Baixos: & $\begin{array}{l}\text { Municípios com menos de } 2000 \text { habitantes e com mais de } 20 \% \text { da sua população activa ocupada na agricultura } \\
\text { excluindo municípios residenciais especiais }\end{array}$ \\
\hline Portugal: & Aglomerações com menos de 10 c00 habitantes \\
\hline
\end{tabular}

Fonte: United Nations Demographic Yearbooks.

A característica comum existente nesta classificação simplista de regiões/ láreas rurais reside na exiguidade da população que nelas habita. Os Países-Baixos dão ainda especial atenção ao tipo de actividade económica em que se ocupa a população, dando relevo ao papel do sector agrícola na definição de ruralidade; e a França inclui uma dimensão espacial.

Holmes (1977) define rural como terras sem gente, encerrando um ambiente inóspito para além do ecuménico, às quais se encontram aliados rendimentos agrícolas baixos e densidades não superiores a 4 habitantes $/ \mathbf{K m}^{2}$. O mesmo autor, em 1981, apresenta uma lista de nove características do mundo rural:

- difícil acessibilidade, que condiciona a actividade económica e repele a fixação de populações;

- a actividade económica centrada na exploração dos recursos naturais que podem potenciar altos rendimentos, mas têm efeitos multiplicadores escassos na economia local; 
- a inospitabilidade do ambiente, que inibe as populações de participarem nas experiências de outras zonas rurais;

- a satisfação das necessidades básicas que se torna difícil e onerosa e requer intervenção governamental;

- os poderes públicos, influenciam de forma decisiva a oferta e manutenção dos serviços, sendo eles próprios, em muitos casos, detentores de maior parte da terra;

- a mobilidade das populações e a sua composição sectorial desequilibrada que mantém a actividade económica em níveis baixos;

- a perda de identidade cultural e a assimilação de valores que não são os seus, o que inviabiliza a estabilidade do tecido económico e social;

- a distância aos centros metropolitanos que conduz à marginalização de importantes aspectos da vida social e cultural; e

- a adopção dos avanços tecnológicos não acompanhado, na maioria dos casos, pela quebra das amarras do isolamento.

Wibberley (1972) define rural como aquelas partes do país que apresentam sinais inequivocos de ser dominante a utilização do recurso terra, quer no presente quer no passado próximo; enquanto que Rogers (1973) refere que num contexto de uso do solo, as zonas rurais compreendem áreas agrícolas e florestais, assim como as de pousio ou as não cultivadas que se mantêm no seu estado natural.

Estas definições apelam à forma de utilização do solo para reconhecer a característica de ruralidade. Ao ser introduzido o elemento humano, os problemas de definição da ruralidade são acrescidos de forma significativa. Paralelamente, surgem definições demográficas, ocupacionais, ecológicas e socioculturais que tentam, de uma forma ou de outra, ultrapassar esta dificuldade (Hoggard; Buller: 1987).

As definições socioculturais têm em comum o facto de distinguirem os comportamentos, as atitudes de pequenos e grandes aglomerados populacionais, pondo em oposição o rural e o urbano. Ao elevado grau de interacção das entidades de comunidades rurais na sua vida quotidiana pela partilha de valores comuns, tornando-os harmoniosos e consensuais, contrapõe-se a diferenciação baseada na classe e estatuto social, que conduz ao conflito das comunidades urbanas.

Palmer et al (1977), ao trabalhar a conceptualização do rural, demonstrou que as suas imagens se estruturam numa série de dimensões que vão desde a acessibilidade até à actividade, passando pelo tipo de povoamento, pelas facilidades de fixação, pela paisagem, pela avaliação (repousante versus perturbadora), pela emoção e pela reflexão. 
Nas definições socioculturais, o objecto da investigação centra-se na ocupação dos habitantes rurais. Este pressuposto é assumido, nas definições ocupacionais, de forma ainda mais marcada. O predomínio da agricultura e da floresta constitui o elemento chave destas definições. Está-se perante a corrente de pensamento que, normalmente, se designou por agriculturarismos apresentada por Glen (1977), Bell e Newby (1974), Buttel (1982), Coughenour; Christenson (1983) e Newby (1980), entre outros. No entanto, uma definição ocupacional baseada em exclusivo no sector primário ignora a importância de sectores como a indústria agro-alimentar, o artesanato e a produção de energia, excluindo-se, de igual modo, as funções de marketing do sector de serviços que têm, igualmente, o seu papel nas zonas rurais.

O processo de urbanização a que se encontra sujeito o mundo rural nos séculos XIX e XX tem merecido a atenção dos investigadores. Johnston (1983) admite três formas diferentes do processo de urbanização:

- um fenómeno demográfico, pelo qual uma parte crescente da população se concentra em áreas urbanas. Esta concentração dá-se, quer pelo êxodo rural para as cidades, quer por diferenciais na taxa de fertilidade e mortalidade entre o mundo urbano e rural. A Figura $n .^{\circ} 3$, ilustra bem este estado de coisas desde 1970;

- um fenómeno económico e social, inerente ao processo de industrialização das economias capitalistas. As áreas urbanas são vistas como entrepostos comerciais e potencializadores de uma concentração da produção, da distribuição e do processo de comercialização;

- um fenómeno de comportamento, em que as áreas urbanas actuam como centros de mudança social.

Maher (1982) identifica como factores-chave de influência das áreas urbanas os avanços tecnológicos, a mudança demográfica, os factores comportamentais, o papel das políticas públicas e a mudança de relações entre estas influências e as estruturas sociais e económicas.

A vulgarização de um contínuo urbano-rural não pode ser visto como um fenómeno unidimensional, mas sim dependente de variáveis sociológicas, demográficas, culturais, políticas e económicas. Burie (1967) definiu esta complexidade numa abordagem tridimensional que envolve as vertentes física, cultural $\mathrm{e}$ social (Fig. n. ${ }^{\circ} 2$ ). 
Figura n. ${ }^{0} 2$

O PROCESSO DE URBANIZAÇÃO DE UM LUGAR IMAGINÁRIO P REPRESENTADO POR UM ESPAÇO TRIDIMENSIONAL, NO TEMPO: $P$ PODE EVOLUIR PARA QUALQUER DOS PONTOS $\mathrm{P}_{1}, \mathrm{P}_{2}$ e $\mathrm{P}_{3}$

Fonte: Burie (1967)

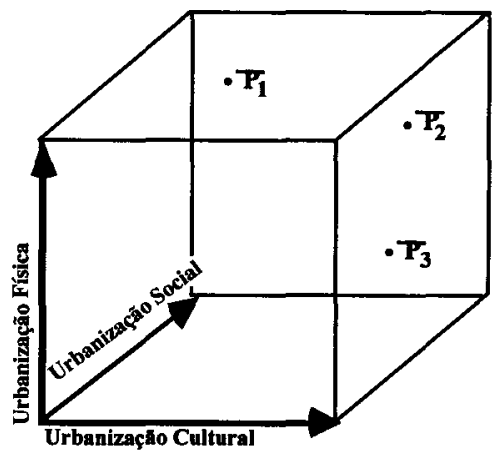

Estes três aspectos do processo podem ser sequenciais e, a longo prazo, coincidentes no tempo. Frankenberg (1966), em vez de abordar a continuidade urbano/rural de forma multidimensional, optou por uma via mais directa, explorando e interpretando a natureza e a evolução de um determinado sistema social (ver quadro . $^{\circ} 4$ ).

Um outro aspecto da dicotomia rural/urbano prende-se com o fenómeno da migração das populações rurais para as áreas urbanas. A este fenómeno não será de todo estranha a perda de activos na agricultura (ver Quadro n. ${ }^{\circ}$ ).

Quadro n. ${ }^{\circ}$

CARACTERÍSTICAS DAS SOCIEDADES URBANAS E RURAIS

\begin{tabular}{|c|c|}
\hline Rurais & Urbanas (menos rurais) \\
\hline - Comunidade $=$ Gemeinschaft & - Associação = Gesellschaft \\
\hline - Campos sociais restrilos & - Campos sociais alargados \\
\hline - Multiplicidade de papéis (multiplicidade de papéis para o mesmo indivíduo) & - Sobreposição de papéis (diferentes papéis para diferentes indivíduos) \\
\hline - Economia simples & - Economia diversificada \\
\hline - Fraca divisão de trabalho (uniformização) & - Extrema diversificaçāolespecializaçăo (diversidadelcomplementaridade) \\
\hline - Status atribuído & - Status adquirido \\
\hline - total = individualidade integral & - parcial = individualidade condicionada \\
\hline - educação de acordo com a posiçāo social & - posiçāo social de acordo com a educação \\
\hline - Protagonismo por vocação & - Protagonismo por compromisso \\
\hline - Ligaçōes em rede fechadas & - Ligações em rede abertas \\
\hline - Local & - Cosmopolita \\
\hline - Classe económica é só numa forma de divisão social & - Classe econónica é a divisão social \\
\hline - Conjunção & - Segregą̧ăo \\
\hline • Integração & • Alienação \\
\hline
\end{tabular}

Fonte: Frankenberg (1966). 
A perda de população conduz ao ciclo vicioso do declínio que foi apresentado por GILG (1983) e que consta da Fig. n. ${ }^{\circ} 3$.

Figura n. ${ }^{0} 3$

A NATUREZA DO CICLO DO DECLÍNIO RURAL

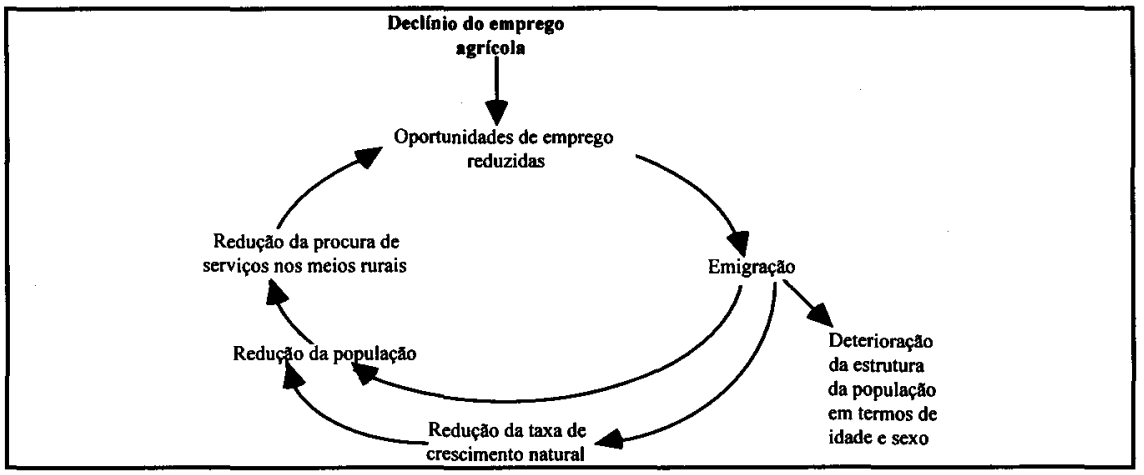

Fonte: Gilg (1983: 95)

Em alguns países desenvolvidos, desde a década de 70, observa-se um fenómeno migratório inverso que se traduz, não só pelo aumento das aldeias dormitórios, mas também pelo das áreas rurais remotas. Este fenómeno é conhecido por contra-urbanização (counter-urbanization). Os aspectos negativos da vida urbana, coadjuvados com uma série de outros factores, contribuíram para esta vaga de contra-urbanização nas últimas duas décadas.

A hierarquização de centros urbanos não é do tipo linear. Se tivermos como pano de fundo a análise temporal para caracterizar o processo de urbanização, o declínio das populações rurais aparece como sendo a outra face da moeda. Assim sendo, a chamada urbanização dos meios rurais poderá ser vista como um processo com três componentes essenciais que encerram tanto os aspectos temporais como espaciais.

A insustentabilidade da função produtivista atribuída à agricultura, principal actividade desenvolvida no mundo rural, aliada ao aparecimento de novos agentes (actores) que entram, na maior parte das vezes, em conflito com os agentes (actores) envolvidos em actividades tradicionais, tanto industriais como agrárias, tem constituído a mola impulsionadora do emergir de novas funções a atribuir ao mundo rural.

As áreas rurais têm uma história económica que assenta numa estrutura baseada no uso do factor terra por actividades agrícolas e florestais e na utilização de especificidades da mão-de-obra rural, com aptidões para determinadas actividades industriais. A regressão verificada na actividade agrícola e a crescente procura de bens rurais para fins ambientais e de lazer têm vindo a constituir factores de 
mudança na forma como estes espaços operam economicamente (CAVALHÉS et al: 1994).

As vantagens comparativas das áreas rurais são normalmente analisadas tendo como ponto de partida, por um lado, a abundância do factor terra (usada para fins agrícolas) e, por outro, as características de uma mão-de-obra orientada para indústrias de mão-de-obra intensiva, isto é, com um tipo de organização baseada no fordismo.

O paradoxo da ruralidade residiria na sua definição pela negativa, isto é, só pode manter-se rural uma região que conhece o declínio ou a estagnação. Na opinião da mesma autora, se uma região conhece um processo de diversificação das suas actividades económicas, mesmo que mantenha o peso estrutural do sector agrário, torna-se difícil, se não impossível, defini-las através da sua oposição face às regiões urbanas. Em alternativa à análise da tipologia espacial que, de uma maneira geral, tem sido adoptada, contrapõe-se uma abordagem local/regional cujo fim consiste na identificação de entidades territoriais pela via das funções que desempenham e do tipo de mudanças que ocorrem no seu seio.

Há algo de diferente, do ponto de vista teórico, nesta abordagem da economia local que a torna distinta do seu uso funcional. As relações entre as economias locais não têm que ser necessariamente concebidas na base da interdependência desigual. Numa perspectiva de globalização, na competição entre as economias locais, há outros tipos de relacionamento entre este tipo de economias com base em diferentes formas de integração, que são normalmente referidas como condições mutuamente vantajosas, contribuindo o seu aparecimento para a existência de uma estrutura de relações e laços não-hierárquicos. De acordo com a abordagem funcionalista, as diferenças espaciais têm por base o desequilíbrio, enquanto na economia local as possibilidades têm um leque mais vasto.

As regiões rurais têm, nos últimos tempos, conhecido um período de mudanças fundamentais, particularmente no que diz respeito à população e ao emprego, para não referir as implicações económicos e sociais das mesmas. As mudanças ocorridas na população e no emprego podem até contrariar a histórica tendência para o seu declínio, sem que concomitantemente se verifique um retorno à situação anteriormente existente. $O$ longo e persistente processo de declínio agrícola continua. Os seus efeitos, sentidos ao nível da na perda de população, têm sido contrariados por um movimento de retorno que em termos económicos não significa que se volte a uma ruralidade tal como aqui era concebida anteriormente, isto é, baseada na actividade agrícola. A actividade económica nas áreas rurais tem ligações cada vez mais estreitas com a economia nacional e internacional.

$\mathrm{Da}$ análise sectorial passou-se a uma abordagem integrada, o que levantou novas questões à problemática do desenvolvimento rural e da política rural. A análise das mudanças do mundo rural coloca uma série de problemas pelo leque variado de características que as áreas não-metropolitanas apresentam que, 
por definição, são localidades com uma população escassa, sediadas em povoações pequenas cujos limites se situam bem longe do seu centro. A economia destas localidades caracteriza-se por ser muito aberta, se tivermos em atenção o intenso comércio que existe entre elas. A interdependência é, por conseguinte, uma palavra-chave.

As mudanças no nível e natureza da actividade económica numa dada região representam o resultado de um número determinado de processos. Os impactos numa certa região dependem das condições locais associadas aos recursos naturais e à evolução histórica que condicionam a capacidade de intervenção das forças regionais, nacionais e até internacionais. Estas mudanças abarcam um certo número de elementos.

Em primeiro lugar, há a referir as mudanças no sector primário, por serem aquelas que têm uma importância maior. O processo de desenvolvimento económico está associado ao declínio do papel empregador do sector agrícola. No último século, para além deste facto, há a realçar que o processo de mudanças tem sido acompanhado por um abandono das regiões rurais, devido ao fenómeno migratório para os centros urbanos. Contudo, o significado do declínio do sector primário tem vindo a perder importância face a outras influências.

Em segundo lugar ocorrem mudanças na actividade económica ao nível do sector não-primário, sobretudo o que produz para colocar fora da região. Estas mudanças são o resultado da produtividade das empresas existentes, da entrada de capital na região e do aparecimento de novas empresas.

Por último, poder-se-ão verificar mudanças no sector de serviços, com origem em alterações na procura de serviços provocados, por exemplo, pela alteração da dimensão e composição da população. $O$ processo de crescimento económico, associado ao desenvolvimento de actividades não-agrícolas fora dos grandes centros urbanos, tem influenciado, de forma significativa, as regiões rurais. Este processo pode ser identificado como sendo da contra-urbanização, que se encontra associado à ênfase dada à diversificação e pluriactividade no sector agrícola. As forças que motivam o desenvolvimento derivam de mudanças que ocorrem tanto na economia nacional/urbana como no próprio seio da economia rural. Elas encerram desde hipóteses vocacionadas para o emprego até às da população.

\section{CONCLUSÕES}

Em resumo, a definição do contexto rural é um problema recorrente que tem vindo a atribular a vida dos investigadores que se preocupam com este tipo de questões. $\mathrm{O}$ conceito de ruralidade é intuitivamente compreendido em termos de imagens e temas que vêm a significar um leque abrangente de coisas para as mais variadas pessoas. A concepção da ruralidade engloba desde definições estatís- 
ticas, baseadas em unidades territoriais, até noções utópicas de formas de viver agrárias.

As definições territoriais são problemáticas porque omitem a dimensão socioeconómica e não têm em devida conta a sua tremenda diversidade. Os agregados nacionais quantitativos, baseados em distorções grosseiras e arbitrárias entre o rural e urbano, têm revelado a sua insuficiência para explicar a dinâmica (quer "positiva" quer "negativa") das economias locais. O uso de instrumentos analíticos e estatísticos mais qualitativos, num contexto local, tem-se revelado muito naais apropriado, uma vez que as áreas rurais são plurais, incluindo pequenas cidades, pequenos aglomerados populacionais, zonas de industrialização rural, $\mathrm{e}$ zonas remotas e selvagens. Todo este mundo plural não pode ser visto como a antítese das comunidades urbanas, uma vez que as suas funções económicas e sociais se tornam, cada vez mais, interrelacionadas. $O$ mundo rural deve ser olhado numa perspectiva das suas interrelações com as outras comunidades, com carácter dinâmico e de constante mudança.

As tipologias de áreas rurais e a conceptualização de ruralidade, por conseguinte, correm o risco de gravitarem em torno de duas posições extremas e insustentáveis: demasiado abrangentes e vagas, e por isso, inoperantes; ou, em alternativa, demasiado restritivas, simplistas e assentes em pressupostos apriorísticos da vida rural. Seria apropriado pensar num contínuo rural/urbano, no qual as comunidades rurais se identificam pela sua capacidade de associação. Esta característica associativa pode ser encarada como uma coincidência de vários factores:

- dimensão da população e densidade populacional;

- afastamento em relação a outros centros populacionais, tanto geográfico como dos centros de tomada de decisão;

- o nível de desequilíbrio sectorial em termos de actividades económicas;

- o grau de identidade local e a segmentação da comunidade e do mercado do trabalho;

- a capacidade de inovação;

- $o$ acesso a serviços e o custo, por habitante, da manutenção de infra-estruturas públicas.

\section{NOTAS}

* Apresentado no Congreso Interdisciplinar - "Valladolid Hoy y Mañana: Presente y Futuro", integrado nas comemorações do IV Centenario da Cuidad de Valladolid. 


\section{BIBLIOGRAFIA}

BELL, C; NEWBY, H. (1974), "Capitalist Farmers in the British Class Structure", Sociologia Ruralis, n. 14 , pp. 86-107.

BONTRON, J. C.; CABANIS, S. et al (1993), Essai de typologie socio-economique des cantons français, Paris, SEGESA-DATAR.

BRYDEN, J. (1994) "Prospects for rural areas in an enlarged Europe". Journal of Rural Studies, vol. 10, n. ${ }^{\circ}$. pp. 387-394.

BULLER, H.; WRIGHT, S. (1990), Rural Development: Problems and Practices, Aldershot, Avebury.

BURIE, J. B. (1967), "Prolegomena to a Theoretical Model of Inter community Variation", Sociologia Ruralis, n. 7 , pp. 347-64.

BUTTEL, F. H. L. (1982), "The Political Economy of Agriculture in Advanced Industrial Societies", Current Perspectives in Social Theory, n. ${ }^{\circ}$, pp. 27-55.

CASTLE, E. N. (1991), The Benefits of Space and the Cost of Distance in the Future Rural America, São Francisco, Rural Studies Series.

CAVAILHÉS, J. et al (1994), "Change in the French Countryside: Some Analytical Propositions", European Agricultural Economics, n. ${ }^{\circ} 21$, pp. 429-449, Berlim, Walter de Cruyter.

CAWLEY, M. E. (1994), "Desertification: Measure Population Decline in Rural Ireland", Journal of Rural Studies, vol. 10, n. 4 , pp. 395-407.

CLOKE, P. J. (1977), "An index of rurality for England and Wales", Regional Studies 11, Cambridge University Press, pp. 31-46.

CLOKE, P. J.; EDWARDS, G. (1986), "Rurality in England and Wales 1981: A replication of the 1971 index", Regional Studies, 20: 4, Cambridge University Press, pp. 289-306.

COFFEY, W. J.; POLESE, M. (1984), "The concept of local development: A stages model of endogenous regional growth", Papers of the Regional Science Association, vol. 55.

COMISSÃO DAS COMUNIDADES EUROPEIAS (1988), o Futuro do Mundo Rural, Comunicação da Comissão ao Conselho e ao Parlamento PSTA/P0/1007, Bruxelas.

COMMISSION DES COMMUNAUTÉS EUROPÉENNES (1993), Notre Avenir Agricole, CECA, Bruxelas.

COUGHENOUR, C. M.; CHRISTENSON, J. A. (1983), "Farm Structure, Social Class and Farmers'Policy Perspectives", pp. 67-86 in Brewster, D. E. et al (eds) Farms in Transition, Ames, Iowa State University Press.

CRAIG, J. (s/d), "Local authority urban-rural indicators compared", Population Trends, HMSO.

CRAIG, J. (1985), "Better measures of population density", Population Trends, n. 39 , HMSO.

CRAIG, J. (1986), "The most densely populated areas of England and Wales", Population Trends, n. ${ }^{\circ} 45$, HMSO.

CRAIG, J. (1987), “An urban-rural categorisation for wards, and local authorities", Population Trends, n. ${ }^{\circ} 47$, HMSO, pp. 6-11.

CRAIG, J.; WEBBER, R. (s/d), "Which local authorities are alike", Population Trends, n." , HMSO.

DINEEN, D. (1988), Local Innovation and Technological Development Strategies to Generate Employ-ment Growth, Report for LEDA Programme, LRDP Consultants, London.

DINIZ, F. (1995), "O efeito da ponderação da dimensão da população e da superfície territorial na medida da densidade populacional". Actas do Seminário Investigação Inovação e Desenvolvimento Trans-fronteiriço III, Janeiro, Covilhã. 
ERRINGTON, A. (1994), "The peri-urban fringe: Europeís forgotten rural areas", Journal of Rural Studies, vol. 10, n. ${ }^{\circ}$ 4. pp. 367-375.

EUROSTAT (1994), Estatísticas de Base da Comunidade de Comparação com os Principais Parceiros da Comunidade, 31.a edição, Serviço de Publicações Oficiais das Comunidades Europeias, Luxemburgo.

FRANKENBERG, R. (1966), Communities in Britain, Harmondswonth, Penguin.

FRIEDMAN, G. (1953),"Villes et Campagne", Deuxiéme Semaine Sociologique, Paris, A Colin.

GILG, A. W. (1983), "Population and Employment", pp. 74-105 in Pacione, M.; Gilg, A. W. (ed) Progress in Rural Geography, Beckenham, Croom Helm.

GLEN, N. D.; HILL, L. (1977), "Rural-Urban Differences in Attitudes and Behaviour in the United States", Annals of the American Academy of Political and Social Science, n. ${ }^{\circ} 429$, pp. 36-50.

HALL, P. (1986), "The New Zealand Urban System: Deurbanization at the Southern Periphery of the Urban World", New Zealand Geographer, n. 42 , pp. 65-69.

HIGGINS, B.; SAVOIE, D. J. (1988), Regional Economic Development - Essays in Honour of François Perroux, Boston, Unwin Hyman Ltd..

HODGE, I. (1986), "The scope and context of rural development", European Review of Agricultural Economics, vol. 13, pp. 271-82.

HODGE, I.; MONK, S. (1991), "In search of a rural economy: Partterns and differentiation in non-metropolitan England", Land Economy Monograph, 20, Department of Land Economy, University of Cambridge.

HODGE, I.; MONK, S. (1991), "Targeting rural areas for special assistance", Land Economy Discussion Paper, 27, Department of Land Economy, University of Cambridge.

HOGGART, K.; BULLER, H. (1987), Rural Development: A Geographical Perspective, London, Croom Helm.

HOGGART, K.; BULLER, H. (1987), Rural Development: A Geographical Perspective, Beckenham, Croon Helm.

HOLMES, J. H. (1977), "Population”. Pp. 331-313 in Jeans, D. N. (ed.), Australia: A geography Sydney, University Press, Sydney.

HOLMES, J. H. (1981), Settlement Systems in Sparsely Populated Regions: The United States and Australia, New York, Pergamon Press.

HOUÉE, P. (1989), Les Politiques de développment Rural-Des Années de Croissance au Temps dilncentitude, Paris, Economica INRA.

JASMA, D. J. et all (1981), "Rural development: A review of conceptual and empirical studies", in Martin, L. R. (ed) Economics of Welfare Rural Development and Natural Resources in Agriculture 1940ís to 1960ís Survey of Agricultural Economics Literature, vol. 3, Minneapolis University, Minnesota Press.

JOHNSTON, R. J. (1983), "Urbanisation". p. 363-4 in Johston R. S. (ed), The Dictionary of Human Geography. 2nd ed, Oxford, Blackwell.

KEYSER, B. (1962), "La domination urbaine", Les Etudes Philosophiques, n. ${ }^{\circ} 2$.

KEYSER, B. (1990), La Renaissance Rurale Sociologie des Campagne du Monde Occidental, Paris Armand, Colin Editeur.

LÉGER, D.; HERVIEU, B. (1979), Le retour á la nature aufond de la fôret a líEtat, Paris, Le Seuil.

LEVADOUX, B. (1989), "Le centre díentrepise et dînnovation: nouvel outil communautaire de regeneration economique local", Revue díeconomie regional et urbaine, $\mathrm{n}^{\circ}{ }^{\circ} 2, \mathrm{p} .306-329$.

LEWIS, C. J. (1979), Rural Communities: A Social Geography, Abbot, David and Charles Newton. 
LEWIS, C. J.; MAUND, D. J. (1976), "The Urbanisation of the Countryside: A Framework for analysis", Geografiska Annaler, n. ${ }^{\circ} 58$ B; pp. 17-27.

LOPEZ, A. (1987), "Le monde rural face au villes", Économie Rurale, 178-179.

MAHER, C. A. (1982), Australian Cities in Transition, Melbourne, Shillington House.

MALASSIS, L. (1979), "Economie agricole, agro-alimentaires et rural”, Economie Rurale, 131.

MARSDEN, T. et al (1993), Constructing the Countryside, London, UCL Press.

MATHIEU, N. (1974), "Propos critique sur líurbanisation des campanhes", Espaces et Societé, n. ${ }^{\circ} 12$.

MATHIEU, N.; JOLLIVET, M. (1989), Du Rurale à líeuvironnement, la Question de la Nature Aujourduíhui, Paris, ARF/líHaimattan.

MAZOYER, L. (1982), "Origines et mécanismes de reproduction des inégalités regionales de développment agricole en Europe", Economie Rurale, 150-151.

MENDRA, H.; JOLLIVET, M. (1971), Les Collectivités Rurales Française Etudes Comparative de Changement social, Paris, Librairie Armand Colin Editor.

MENDRAS, H. (1959), Sociologie de la Campagne Francaise, Paris, PUF col. "Que sais-je?"

MOSHER, A. T. (1972), Projects of Integrated Rural Development, Nova York, Agricultural Development Council.

MURDOCH, J.; PRATT, A. C. (1994), "Rural studies of power and the power of rural studies: a reply to philo", Journal of Rural Studies, vol. 10, n. ${ }^{\circ}$ 1. pp. 83-87.

NEWBY, A. (1980), Green and Pleasant Land? Social Change in rural England, Harmondswooth, Penguin,.

OíCINNEID, M. S.; KEANE, M. J. (1990), “Applying strategic planning to local economic development: The case of Connemara Gacltacht, Ireland", Town Planning Review, 64, 4.

OCDE (1988), Formulation de la Politique Rural - Nouvelles Tendances, Paris, OCDE.

OCDE (1990), Rural Development Policy, Paris, OCDE.

OCDE (1991), Nouvelle Gestion des Service dans les Zones Rurales, Paris, OCDE.

OCDE (1993), What Future for Our Countryside? A Rural Development Policy, Paris, OCDE.

OECD (1983), Urban Statistics in OECD Countries, Paris, OECD.

PALMER, C. J.; ROBINSON M. E.; THOMAS, R. W. (1977), "The Countryside Image: An Investigation of Structure and Meaning", Environment and Planning, A: 9, pp. 739-49.

PEARSON, L. O.; WESTHOLM, E. (1994), "Towards the New Mosaic of Rural Regions", European Agricultural Economics, n. 21 , pp. 409-427, Berlin, Walter de Cruyter.

PECQUER, B.; SILVA, M. R. (1992), "A Territory and Economic Development: The example of diffuse industrialisation", in GAROFOLI, G. (1992), Endogenous Development and Southern Europe, Aldershot, Avebury.

PECQUEUR, B. (1989), Le Développement Local, Paris, Syros/Alternatives Économiques.

PETIT, M. (1982), "Les economistes ruraux face aux problémes de líagriculture et du développment régional en Europe", Economie Rural, n. $150-151$.

POUR (1984), "Le développment agricole et rural: un tournant?, Privat, $n .^{\circ} 93$, Toulouse Janvier-Février.

POUR (1984), "Les nouvelles solidarités en milleu rural", Privat, n. ${ }^{\circ} 96$, Toulouse Julliet-Août.

POUR (1988), "1992: Territoires en question, questions de territoires" Privat, $\mathrm{n}^{\circ}{ }^{\circ} 118$, Toulouse, Sept.-Oct..

POUR (1988), "LiEurope rurale a líheure des choix", Privat, n. ${ }^{\circ} 115-116$, Toulouse Mars-Join.

RAMBAUD, P. (1969), Societá Rural et Urbanisation, Paris, Le Seuil. 
RIBEIRO, M.; DINIZ, F. (1995), "Turismo rural enquanto alternativa de regiōes desfavorecidas: Potencialidades e limites". 3. ${ }^{\circ}$ Congresso Internacional da Associação Mediterrânea do Turismo, Abril, Estoril.

ROBINSON, Guy M. (1990), Conflict and Change in the Countryside, England, John Wiley \& Sons Ltd.

SARACENO, E. (1994), "Alternative Readings of Spatial Differentiation: The Rural Versus Local Economy Approach in Italy”, European Agricultural Economics, n. ${ }^{\circ} 21$, pp. 451-474, Berlim, Walter de Cruyter.

SARACENO, E. (1994), "Recent trends in rural development and their conceptualisation", Journal of Rural Studies, vol. 10, n. ${ }^{\circ}$. pp. 321-330.

SCHUMACHER, E. F. (1980), Small is beautiful (um estudo de economia em que as pessoas também contam), Unversidade Moderna, n. ${ }^{\circ}$ 65, Lisboa, Publicações D. Quixote.

STERN, E. (1990), "Evaluating Programmes and Projects for Economic and Social Integration", Paper presented at a European Seminar on Evaluation Approaches and Methods, Associação in LOCO, Algarve, Portugal.

STÖHR, W. (1992), "Local initiative networks as an instrument for development of peripheral areas, in Tykkyläinen, M. Development Issues and Strategies in the New Europe: Local, Regional and Interregnal Perspectives, Aldershot, Avebury.

STÖHR, W. B. (1990), Global challenge and local response, London and New York, The United Nations University.

TÖNNIES, F. (1963), Community and Society, New York, Harper and Row.

TYKKYLÄINEN, M. (1992), Development Issues and Strategies in the New Europe: Local, Regional and Interregnal Perspectives, Aldershot, Avebury.

UNITED NATIONS (1990), United Nations Demographic Yearbooks.

VÁZQUEZ-BARQUERO, A. (1992), "Local development and flexible accumulation: Learning from history and policy", in GAROFOLI, G. (1992), Endogenous Development and Southern Europe, Avebury, Aldershot.

WIBBERLY, G. P. (1972), "Conflicts in the Countryside", Town and Country Planning, n. 40 , pp. 259-264.

WOODS, R. I. (1985), “Towards a General Theory of Migration”, Pp. 1-5, in Van der Knapp G. A.; White, P. E. (eds) Contemporary Studies of Migration, International Symposia Series, Geo. Books Norwich.

WORLD BANK (1991), Social Indicators of Development 1990 - Data on Diskette. Washington D. C.

WORLD BANK (1991), World Development Indicators 1991 - Data on Diskette, Washington D. C.

WORLD BANK (1991), World Tables 1991 - Data on Diskette, Washington D. C. 